\title{
Amateur paleontological societies and fossil clubs, interactions with professional paleontologists, and social paleontology in the United States
}

\author{
Bruce J. MacFadden, Lisa Lundgren, Kent Crippen, \\ Betty A. Dunckel, and Shari Ellis
}

\begin{abstract}
Considerable interest exists among lifelong learners in the USA about fossils and the science of paleontology. Unlike some other science-related groups, e.g., astronomy and ornithology, interest in fossils among amateur paleontologists is primarily focused within local clubs and societies with little national coordination. This paper presents the results of formative evaluation of the FOSSIL project, conducted after the project "Kickoff" meeting held at the NAPC (North American Paleontological Convention) in 2014. FOSSIL is developing a national networked community of practice that includes amateur and professional paleontologists. Our research indicates that more than 60 amateur fossil clubs and societies exist in the USA, of which almost 40 have elected to be part of the FOSSIL network. Overarching goals of this program include enhanced collaborations between amateurs and professionals, knowledge-building about paleontology, access to resources for lifelong learning, and development a viable learning community of practice focused on topics of common and societal interest, such as collections (including digitization), evolution, climate change, and K-12 outreach. In addition to more traditional means such as list-serves and newsletters, FOSSIL is developing an online community (myFOSSIL) and using social media (Facebook and Twitter) to foster communication and interactions among stakeholders, and thus promoting the concept of "social paleontology".
\end{abstract}

Bruce J. MacFadden. Florida Museum of Natural History, University of Florida, Gainesville, Florida 32611 USA, bmacfadd@flmnh.ufl.edu

Lisa Lundgren. School of Teaching and Learning, College of Education, University of Florida, Gainesville, Florida 32611 USA, lisa.lundgren@ufl.edu

Kent Crippen. School of Teaching and Learning, College of Education, University of Florida, Gainesville, Florida 32611 USA, kcrippen@coe.ufl.edu

Betty A. Dunckel. Florida Museum of Natural History, University of Florida, Gainesville, Florida 32611 USA, bdunckel@flmnh.ufl.edu

Shari Ellis. Florida Museum of Natural History, University of Florida, Gainesville, Florida 32611 USA, sellis@ufl.edu

Keywords: amateurs; clubs; paleontology; professionals; societies; United States

MacFadden, Bruce J., Lundgren, Lisa, Crippen, Kent, Dunckel, Betty A., and Ellis, Shari. 2016. Amateur paleontological societies and fossil clubs, interactions with professional paleontologists, and social paleontology in the United States. Palaeontologia Electronica 19.2.1E: $1-19$

palaeo-electronica.org/content/2016/1471-commentary-amateur-professionals-in-us 


\section{INTRODUCTION}

Ever since the widespread establishment of natural history museums in the USA during the $19^{\text {th }}$ and early $20^{\text {th }}$ centuries, and with the help of charismatic fossils such as dinosaurs, paleontology has developed as an intrinsically interesting science domain to the general public (e.g., Plotnick, 2007). During the second half of the twentieth century, many fossil interest groups, clubs, or societies developed, oftentimes in association with local museums (or universities), as a way to promote common interests and activities in paleontology among amateurs and professionals. While descriptions of professional paleontological societies (e.g., Paleontological Society and Society of Vertebrate Paleontology) can be found in the literature (e.g., Priscum, 2016; SVP, 1941-2010; Archangelsky et al., 2000), little is chronicled about the development of amateur fossil clubs and societies in the U.S. Knowledge about these individual fossil clubs and societies is typically contained in their newsletters, archives, and when available, on their web sites, but no single place currently exists where this information is compiled or systematically documented. Likewise, the contributions of individual amateurs to the discipline of paleontology are manifold, but oftentimes are poorly documented or recognized (Catalani, 2014).

In 2012 and 2013, we began a project to better understand the status of fossil clubs and societies, their members, and associations with professional paleontologists and museums in the USA. We previously conducted a front-end needs assessment (sensu Diamond et al., 2009) to better understand our audiences (Crippen et al., 2016). In

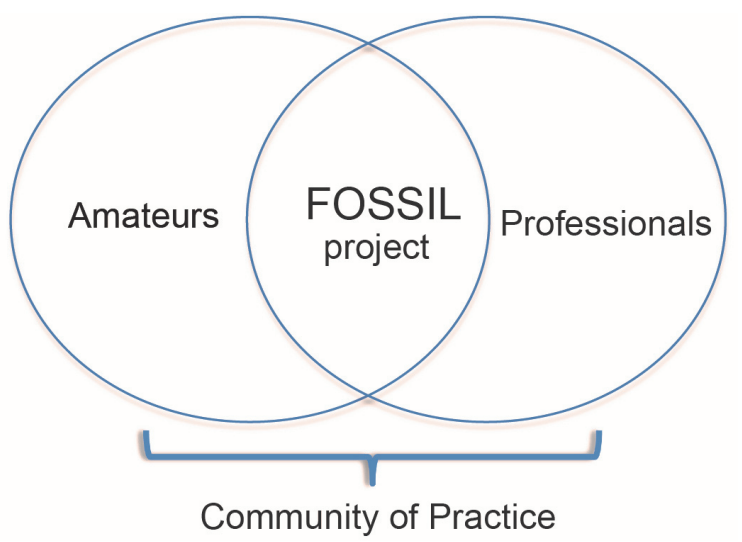

FIGURE 1. Theoretical learning model for social paleontology in which amateur and professional paleontologists come together via the FOSSIL project within the framework of a Community of Practice.
2013 we started a project called FOSSIL (www.myfossil.org). In 2014 we conducted a formative evaluation (sensu Diamond et al., 2009) with amateur and professional paleontologists in the USA to obtain their feedback regarding the development of the FOSSIL program components. This paper describes the FOSSIL project, which is developing a national networked community of practice (CoP, Figure 1; sensu Lave and Wegner, 1991; Wenger et al., 2002) that integrates fossil clubs, societies, amateurs, professionals, museums, and related institutions throughout the USA. With this background in mind, the purpose of this paper is to present: (1) the results of the formative evaluation conducted in 2014; and (2) qualitative observations, insights, and best practices developed since we conducted the formative evaluation, including the emergence of what we call "social paleontology".

\section{THEORETICAL LEARNING FRAMEWORK}

\section{Community of practice}

A community of practice (CoP) is a theoretical term used to describe the social learning of a group of people through a shared practice related to a domain of knowledge (Lave and Wenger, 1991; Wenger et al. 2002). In our case, the group is comprised of amateurs and professionals who are interested and engaged in the practice of paleontology. The act of doing paleontology as a social process is the core learning mechanism for the community (and also relates to our concept of social paleontology described below). Thus, learning is defined not as an accumulation of knowledge within an individual, but as participation within a group that involves the use of evidence, theories, and tools in shared approaches or best practices of discovery, problem solving, and communication (Wenger, 1998). Such forms of participation can occur through formal (i.e., structured, school related) and informal (i.e., voluntary, interestdriven) experiences.

Membership within a CoP is viewed through the lens of legitimate participation and occurs along a continuum from novice to recognized expert. Legitimate participation is a euphemism for social learning, the embodiment of becoming something, an expert. The process of professionalizing one's membership is defined by enculturation, a process brought about through social interaction and appropriation of the cultural activity of the domain. For paleontology, this activity includes observing fossil evidence and analyzing it in order to model past 
life, constructing theoretical arguments and communicating this process through various dissemination modes such as presentations and publications. Legitimate professional practice includes such elements as vocabulary, skills, techniques, stories, symbols, and routines, as well as related social dimensions (Kienle and Wessner, 2005).

Communities of practice have been promoted and identified in a range of domains, including science (Kienle and Wessner, 2005) and education (US Department of Education, 2011) as well as business and industry (Gongla and Rizzuto, 2001). In addition, the Association of Science -Technology Centers (ASTC, 2016) and CAISE (2016) currently support and facilitate CoPs as an effective means for growing informal science education. In nearly all of these cases, online communication is highlighted as a critical and contemporary factor for determining success. Astronomy from the Ground Up (www.afguonline.org/), Encyclopedia of Life (eol.org/), and eBird (ebird.org/) are all current examples of online CoPs that are based upon engaging the public in science (i.e., citizen science; e.g., Bonney et al., 2009).

\section{Social paleontology}

Our experience with the FOSSIL project over the past several years clearly demonstrates the value of the social dimension of learning within the context of twenty-first century communication. As such, we envision social paleontology as open and collaborative knowledge-building discourse related to the domain of paleontology among people of all demographics via technology. This inclusive practice of discovering and learning together includes the use of popular social media such as Facebook and Twitter as well as our online community site. One role of the FOSSIL project is to act as the technology steward to mediate the CoP and provide leadership in addressing the goals and needs of the community. Thus far, our research has identified three general themes that represent the practice of social paleontology: (1) making connections of groups of people, objects (fossils), and locations (geography) based on shared attributes; (2) making observations, i.e., recording, building, and maintaining information about objects (fossils) that exist or have existed in the real-world; and (3) having conversations, i.e., collaborative discourse among people that includes the sharing of various information resources (Crippen et al., 2016).

\section{Intended primary audiences: Definitions}

Amateur paleontologist. A person who engages in collecting fossils and learning about paleontology as a pastime and without compensation; nor as a profession (also see Hooks, 2005). Synonyms that have typically been used in place of "amateur" include "avocational," "hobbyist," and "citizen," although Crippen et al. (2016) found a preference among these individuals for the term "amateur".

Professional paleontologist. A person who is paid to do, teach about, or interpret paleontology as his/her profession, typically at a museum, university, college, or governmental agency. The scope of this definition also includes consulting paleontologists, e.g., working on fossil resource assessment and mitigation.

This paper is focused on the interactions between amateur and professional paleontologists. We also realize that there is a third potential audience, i.e., the commercial paleontologist, defined as a person who sells fossils. The interactions between and among commercial paleontologists and amateur and professional paleontologists, which has had a complex history (see recent, differing points of view, e.g., Pringle, 2014; Shimada et al., 2014; Larson et al., 2016), is outside the intended scope and design of this study.

\section{BACKGROUND: SUMMARY OF FRONT-END EVALUATION 2012}

Prior to 2013, there was no single place where one could go to understand the paleontology community throughout the USA that includes amateurs, professionals, and other related stakeholders. Crippen et al. (2016) present the results of a frontend evaluation (sensu Diamond et al., 2009) of amateur and professional paleontologists and their organized activities and connections to museums. We summarize their findings here because they provide important background for the formative evaluation and other observations presented below. Electronic surveys were sent to our relevant target audiences in fall 2012; responses were received from 30 clubs and 42 professional paleontologists. Because of the two different initial target audiences for the front-end surveys, we first summarize the results for the fossil clubs and societies and then discuss those of the professional paleontologists. 


\section{Amateur paleontologists and organizations (clubs and societies)}

The 30 fossil clubs and societies that responded have been in existence for a maximum of 65 years (Dry Dredgers, from the Cincinnati region of Ohio, is the oldest) and many have been active for decades (mean age of clubs is 30 years). The purpose and mission of the clubs are varied, but relevant core ideals include promoting the science of paleontology, collecting fossils, learning, dissemination, and social aspects. The clubs are typically non-profit and geographically focused with a region in the U.S., i.e., there is no national amateur fossil club or society. Most clubs have a modest annual membership fee that is used to defray the costs of their activities and additional revenues are typically raised by sales, auctions, and fairs. At the lower end of the financial spectrum, one club prides itself in charging its members " $\$ 3$ per year, or three years for \$10" (MacFadden, personal observation, 2015).

These individual organizations range in size from 12 to 600 members (mean $=170$ ), with larger clubs primarily located in urban and suburban areas. Rural clubs are not common. The age of individual club members is reported to range from 1 to 95 (these extremes seem to be outliers), with the distribution skewed towards members older than 30 years of age. The lack of younger members ( $<30$ years old) is of concern to some organizations. This also reflects the demographic trends of many lifelong learners and their hobbies, not just in the USA but also elsewhere, e.g., the United Kingdom (Lloyd et al., 2012). The gender diversity is roughly $50 \%$ males $/ 50 \%$ females for most of the clubs. More than half of the clubs self-identify as not particularly diverse. The vast majority of clubs consist predominantly of white members; the minority representation is Hispanic/Latino, particularly in regions where they are well represented in the general population.

Professionals typically have been reluctant to refer to members of paleontological societies and fossil clubs as "amateurs" (see Hooks, 2005). Although the word amateur takes from its Latin root amor- to mean "love" (Brown, 1956), in common usage it has the baggage of being less esteemed, e.g., a person inexperienced or unskilled in a particular activity or "amateurish," meaning characteristic of an amateur, especially in having faults or deficiencies (www.dictionary.reference.com). The majority of non-professionals prefer the name "amateur paleontologist" (57\%), followed by "avo- cational paleontologist" (17\%), "citizen paleontologist" $(10 \%)$, and "hobbyist paleontologist" (10\%) (Crippen et al., 2016). From these survey results, we have been using the term amateur.

Of the 30 amateur organizations that were surveyed, $40 \%$ refer to themselves as a "society" and $27 \%$ as a "club," (other designations included "academy," "friends," "protectors"), whereas $43 \%$ used the adjective "fossil" (e.g., club) and 40\% used the adjective "paleontological" or noun "paleontology" in their name. Over the past several years at least one organization has changed its name from a "club" to a "society," which was related to their incorporation and an increased sense of purpose and credibility, e.g., when seeking outside funding (e.g., grants) for programs (Ferrara, 2015). The relative emphasis on these words as part of organizational self-identity is illustrated in Figure 2.

More than half of the organizations $(60 \%)$ meet on a regular monthly basis; others meet every two months, or once or twice a year. The monthly meetings typically include announcements, conducting the business of the organization, a presentation (such as a talk, oftentimes by an invited speaker), and time for comparing fossils, general group discussion, refreshments, and socializing. Other club activities include training and workshops, publishing a newsletter, website, fossil fairs and festivals, and student scholarships. By far the most popular activity common to these organizations is field trips, primarily to collect fossils.

Thus, one of the common denominators among the clubs is the desire of their members to collect fossils and make their own private collections, either for personal use, to donate to museums, and/or sometimes to trade and sell. Of relevance to the FOSSIL project, these collections are typically used to: (1) learn about fossils and life of the past; and (2) make, organize, and display fossil collections; e.g., including at home, schools, and fossil fairs and festivals.

One respondent noted that the reason they collected fossils is for "fun," and indeed the name of one of the clubs is "Fossils for Fun." There also can be a competitive, or gaming aspect to collecting fossils. Accordingly, some respondents expressed a sense that within a group collecting fossils on a field trip, end-of-day comparisons of what each person found (e.g., biggest, rarest, best preserved, etc.) provided additional motivation along with the thrill of discovery. 


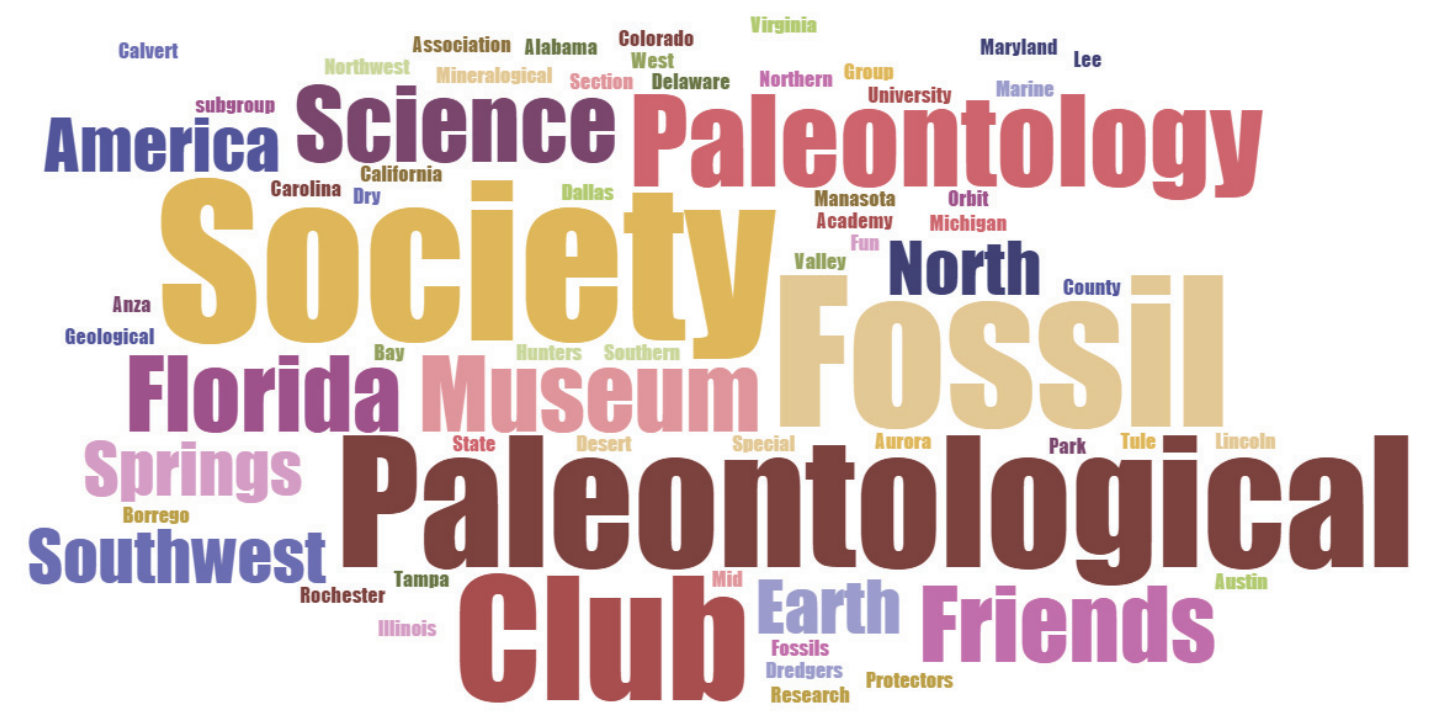

FIGURE 2. Word cloud illustrating the relative use of different words in the names of the 30 fossil societies and clubs that participated in the front-end evaluation. The size of the word relates to its frequency of occurrence.

\section{Fossil collections and digitization}

Although there are no currently reliable estimates, there may be upwards of 100 million fossil specimens contained in the paleontological research collections across the USA. One of the strategic goals of the FOSSIL project is to advance the digitization of these fossils for access to users such as amateur paleontologists. Digitization is defined as: (1) developing an electronic database of specimen catalogs; (2) attaching images, either consisting of 2D photos or 3D scanned images to the electronic database (Cunningham et al., 2014); and (3) the possibility of attaching other related resources, including media (videos), field notes, ancillary data, and relevant publications. Likewise, there is a further expectation that digitized resources such as fossils are made available online through a web portal such as iDigBio (2015). The push to digitize the nation's natural history collections (Page et al., 2015) has immense potential for unrivalled access to fossil collections and related resources (Uhen et al., 2013). The amateur fossil organizations surveyed overwhelmingly $(96 \%)$ indicate they would be interested in digitization activities. Similar initiatives are underway, e.g., in Germany where about 120 amateur and professional paleontologists are digitizing fossils within the foraminifera.eu database (FEUDAT) project (Heseman, 2015).

\section{STEM Learning}

One goal of the FOSSIL project is to enhance science learning as broadly defined by the "strands of science learning" framework (National Research Council, 2009). The six strands include: (1) excitement, interest, and motivation; (2) knowledge; (3) asking and answering questions and evaluating evidence; (4) understanding science as a way of knowing; (5) engaging in science; and (6) identifying as a science learner and contributor. A wide variety of out-of-school experiences make important contributions to adult science learning (Falk et al., 2007; Falk and Needham, 2013). However the role of paleontology in fostering adult amateurs' understanding of science has not previously been explored. Our front-end evaluation analyzed both the background knowledge and interest of the respondents to the following topics that provide opportunities for learning across the science strands: (a) paleontology as a scientific discipline; (b) identifying and organizing fossils and fossil collections ("curation"); (c) fossil collections in U.S. natural history museums; (d) geology as it relates to fossils; (e) evolution based on the fossil record; and (f) climate change interpreted from the fossil record. We found high levels of interest in these topics, suggesting high motivation for further learning (Crippen et al., 2016). Also, paleontology encompasses two "hot-button" topics of broad societal relevance today, i.e., evolution and climate change (e.g., Leshner, 2010). Interest in these two topics are similar to the others, perhaps suggesting 
a lack of bias or misconception that potentially could have affected perceived knowledge or interest.

Crippen et al. (2016) report that $90 \%$ of amateur organizations have an association with professional paleontologists. The role of the professional paleontologist may include: identifying specimens, giving talks, participating as a member, leading field trips, serving as an advisor or part of the leadership, and engaging in field work. Likewise, 93\% of the respondents indicate their organization has a relationship with a museum or other informal science institution (e.g., park, nature, or science center). Activities and interactions with these institutions include donating specimens, volunteering, outreach, and the institution hosting meetings for the organizations.

Prior to administering the survey in 2012 and based on personal experience of the authors (e.g., BJM), there was a perception of barriers that separate the amateur and professional communities. Nevertheless, $65 \%$ of amateur respondents did not believe there were barriers and that the working relationships between these two communities was good; $31 \%$ did think there were barriers. The FOSSIL project is working towards mitigating these barriers regardless of whether they are perceived or real (also see further discussion below).

Ninety-seven percent of the amateur clubs and societies maintain a website, and depending upon the organization, between 50 and $100 \%$ of members use email as a means of communication. List-serves are not popular $(17 \%$ of clubs use these) and when this survey was conducted in 2012, some clubs reported using Facebook. With regard to the Internet, respondents perceive that it is being used by their members to access museum and other club websites, scientific articles, online image galleries, and social media such as Facebook. Eighty-three percent of the organizations publish a newsletter. These organizations historically have not had much communication with peer organizations outside of their respective region. In fact, almost two-thirds (64\%) of the organizations report no coordination of activities with other fossil organizations. Of the remaining one-third $(36 \%)$ that have done jointly sponsored activities with other organizations, by far the most frequent activity includes paleontological field and collecting trips.

\section{Professional paleontologists' point of view}

Professional paleontologists include professors, typically in geology or biology; museum administrators (e.g., directors); curators; collection managers and other support staff (e.g., preparators); and resource managers and contractors. Eighty-two percent report an affiliation with a museum, typically as curators or managers of a paleontology collection. More than half of these collections are available to some degree (e.g., portions or all of the particular collection) in a searchable format on the web, although some are still relegated to "Dark Data," i.e., not accessible on the web.

Eighty-one percent of respondents indicated they have interacted with fossil clubs and their members, and they have been involved in a variety of roles and tasks. By far the most common interaction that professional paleontologists have had with amateur organizations is to present talks and identify fossils. In terms of the extent of their involvement with amateur organizations and their members, 25\% respond "Significant," 16\% "Moderate," and 59\% "Minimal." The most frequent reason for not spending more time with amateurs is "lack of time" (i.e., given their other professional responsibilities).

Seventy-one percent of members of fossil clubs and societies have access to the physical collections curated by professionals. About half of the professional paleontologists report amateurs volunteering in their collections, and/or assisting with related activities. These volunteers contribute cumulatively tens to thousands of hours to tasks such as: preparing specimens, entering data into a catalog or database, collecting fossils, identifying and cataloguing fossils, working in archives, photographing fossils, screen-washing fossils, and providing tours and other forms of outreach.

Fifty-four percent of professional paleontologists responded that there are barriers to interactions with amateur organizations. It is interesting to note that a seemingly greater percentage $(54 \%)$ of professionals perceive there to be barriers relative to the response from the amateurs (25\%).

In summary, the two primary target audiences, i.e., amateur and professional paleontologists, have many commonalities, including fossil collecting, developing collections, and learning about the science of paleontology. Previously there has been no common "space" where these stakeholders could come together on a national level in the U.S. This is a strategic goal of the FOSSIL project by developing the CoP. 


\section{BUILDING CONNECTIONS AND COMMUNITY: FORMATIVE EVALUATION 2014}

The results of the front-end evaluation (Crippen et al., 2016) demonstrate both the need and interest in developing a national network linking amateur paleontological clubs and societies, professional paleontologists, and museums, and similar institutions in the USA. According to Wenger et al. (2002), this constitutes the initiation phase for building a community of practice (Figure 1). Once the community is identified, then the next phase is building the community, oftentimes facilitated by a "launch" event.

The FOSSIL project was funded by a National Science Foundation grant in October 2013. We launched the FOSSIL project with a Kickoff Meeting concurrent with the $10^{\text {th }}$ North American Paleontological Convention (NAPC) held in Gainesville, Florida in February 2014. The NAPC organizing committee specifically intended to welcome amateurs, for whom many we later realized was their first large professional-oriented meeting. All registrants were free to attend the convention talks, social events, and related activities. Within NAPC we hosted a day-long symposium entitled: "Celebrating Public Participation in Paleontology," during which two of the 10 talks were presented by amateurs, along with four posters by amateurs. We also embedded a one-day FOSSIL meeting, which we titled "Building Connections," within the convention, as well as held a special post-meeting field trip for amateur attendees. One or more members of 34 fossil societies and clubs attended the NAPC meeting.

A formative evaluation was conducted by our external project evaluators, Audience Viewpoints Consulting (AVC, 2015). An e-survey instrument (Appendix 1) was distributed to amateurs and professionals a few weeks after the NAPC and FOSSIL Kickoff Meeting. Forty-nine surveys were distributed; 40 participants responded with a completed survey, including 33 of 40 self-identified amateurs (response rate $83 \%$ ), and likewise seven of nine professionals (78\%). These relative responses rates are considered high and acceptable rates for on-line survey instruments (Manfreda et al., 2008; Shih and Fan, 2008). We realize that the survey represents responses from a limited sample and is likely biased towards participants who are predisposed to collaboration. It therefore is neither representative nor generalizable to all members of these two target audiences within the
USA. The results, however, are relevant to further understanding the intended target audiences of the FOSSIL project.

\section{Participation, expectations, and "vibe" during NAPC}

All $40(100 \%)$ of the respondents attended the Monday NAPC symposium "Celebrating Public Participation in Paleontology," and there was strong attendance at other FOSSIL-related activities, e.g., $88 \%$ at the embedded FOSSIL meeting (lunch, keynote talk, workshop, and brainstorming sessions). Of the respondents (amateurs and professional pooled), $85 \%$ reported their expectations were met or exceeded (i.e., with ratings of either 6 or 7 on a scale of 1 to 7 ). It should also be noted that $28 \%$ of attendees, mostly amateurs, were unsure about their preconceived expectations because they had never been to a large professional paleontological conference before. For example:

"I did not know what to expect [-] never been to a conference but once I [got] into the activities it was a great learning experience."

On a scale of 1 to $7,88 \%$ of respondents felt "Welcome" (6) or "Very Welcome" (7) at the NAPC. In a similar open-ended question, there was a general pattern ( $20 \%$ of respondents) that the meeting was inclusive and welcoming to both the amateurs and professionals. For example:

"I felt it was a wonderfully inclusive meeting since the amateur community also participated."

"If they [the professionals] are sincere it seemed that they were reaching across the aisle to interact with amateurs. I found that very refreshing."

Participants were asked to indicate which sessions they considered to be the most useful. The largest number of respondents $(30 \%)$ considered those pertaining to education and outreach to be the most useful, followed by the FOSSIL project $(16 \%)$, and academic (16\%) sessions. Openended responses to these topics included the following preferences:

"Innovations in outreach education in paleo."

"The FOSSIL project round tables and discussions."

"The keynote speakers were inspiring, and three of the academic lectures were on topics I study, while the sessions on public outreach were very easy to follow..." 


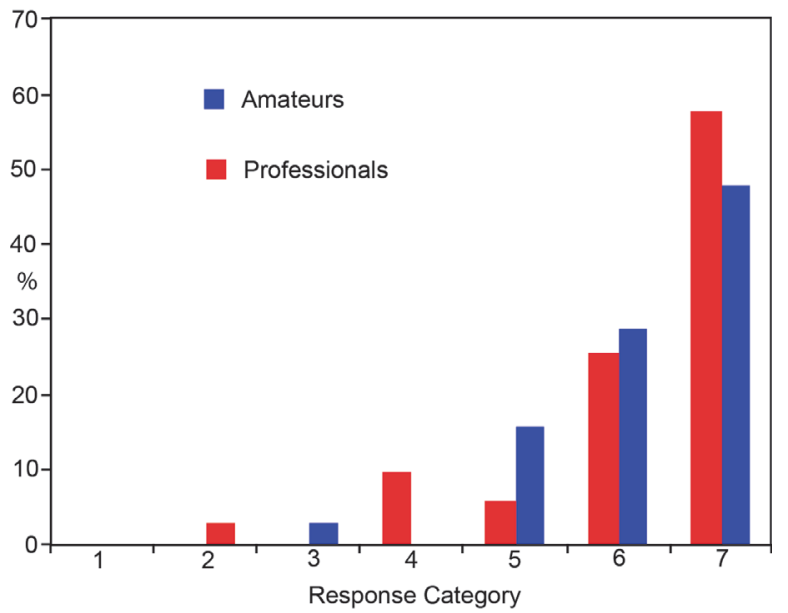

FIGURE 3. Perceived comfort (\%) of amateur respondents contacting other amateurs versus professionals. Along the x-axis, 1 represents "Not comfortable," whereas 6 is "Comfortable," and 7 is "Very Comfortable."

\section{Building connections}

Following along with the process of building an integrated CoP (Wenger et al., 2002) that includes both amateurs and professionals (Figure 1 ), as mentioned above, the theme of the embedded FOSSIL component of the meeting was "Building Connections." For many of the amateur respondents, this was the first time they attended a professional paleontological meeting and, in so doing, had the opportunity to observe professionals practice and communicate what they do in a formal learning setting. Sixty-two percent of the presumed amateurs indicated there was "Sufficient" $(34 \%)$ or "More than Enough" (28\%) opportunities to interact with professionals during the conference. Likewise, as Crippen et al. (2016) reported, typically most members of amateur clubs and societies do not have much contact with members of other clubs, particularly those that are geographically more distant. (An exception to this might be the multiple organizations in Florida, which are within a few hours of each other and report interactions and joint activities.) Nevertheless, although the history is one of little long-distance interaction, $83 \%$ responded that they were either "Comfortable" $(26 \%)$ or "Extremely Comfortable" $(58 \%)$ contacting another fossil club or society member who they do not know. Likewise, a similar number $(84 \%)$ of amateurs were either "Comfortable" $(29 \%)$ or "Extremely Comfortable" (48\%) contacting a professional paleontologist (Figure 3). (We did not ask the similar question of the professionals about con- tacting amateurs.) Despite this strong willingness to connect, it would be disingenuous to suggest that no barriers continue to exist in building these connections.

Respondents were asked if the development of a national network such as FOSSIL might enhance building a community that includes both amateurs and professionals, and also how it would advance the science of paleontology. More than half of respondents indicated the network would enhance collaboration between professional and amateurs (55\%). Twenty-nine percent indicated it provided a means for validation of (amateurs') contributions, and $26 \%$ said it would provide access to resources/artifacts. One respondent commented:

"Make them feel more connected to the science of paleontology as active contributors."

Relevant to connecting and building community, one respondent indicated:

"I can see the opportunity to interact with other groups across the country and build collaborations, plus connect with the professional community."

\section{Perceived benefits}

For any nascent collaboration, or one in which participants become more engaged in common activities and networking, there need to be mutual benefits, either perceived and/or realized, otherwise the collaboration will be difficult to sustain. For both groups some of the most important perceived benefits include access to fossils and associated resources, collaborations, and improved relationships between professionals and amateurs. In the end, the discipline will advance because:

"Professional paleontologists will get to see and study fossils they may not have had a chance to do before."

"Amateur paleontologists will have more opportunities to connect and do publishable work with professionals. Some amateurs already do this. I think amateur paleontologists will gain a level of respect they deserve."

\section{Barriers}

Any project such as FOSSIL that seeks to develop a national network bringing together two seeming disparate audiences likely has potential barriers to success. One-quarter $(27 \%)$ of all of the responses mention the issue of trust between amateurs and professionals. A related issue is that some respondents indicate amateurs do not receive proper credit and likewise do not feel vali- 
dated for their contributions to paleontology. These feelings are exemplified as follows:

\section{"The relationship between the amateur and professional paleontologists is sometimes strained with a lot of suspicion on both sides." \\ "Trust. Some of the clubs are still afraid that the museum will [invoke] 'eminent domain' and take fossils away." \\ "Getting past the bias between amateur and professional." \\ "Anti-amateur attitude of certain academics." \\ "Getting the credit/recognition for a fossil donation." \\ "Professionals...don't see anyone without credentials as worth their time."}

On the other hand, the professionals we surveyed were unanimous that amateurs are both enthusiastic and knowledgeable about paleontology, plus more than half $(57 \%)$ indicate amateurs are dedicated and hard-working. These data belie the perception from amateurs of a lack of respect from the professionals. We also realize that this result might represent sampling bias, i.e., the professionals who responded to this survey are predisposed to working with amateurs and therefore are not representative of the entire professional community.

The influence of commercial paleontologists was brought up by a few $(6 \%)$ respondents, for example:

\section{"The problem of commercial sale of fossils. Controversy over selling fossils-some professionals refuse to interact with amateurs because of this issue."}

Thus, there is a perception among some amateurs that professionals "lump" all non-professionals into a single category that includes both amateur and commercial paleontologists, when in fact many individuals within these groups have very different objectives for why they engage in the pursuit of fossil collecting.

Other respondents indicate logistics and remoteness as barriers to bringing professionals and amateurs together. The responses from the survey include: (1) the lack of cyberconnectivity that potentially excludes some prospective participants; and (2) timing, i.e., professional paleontologists oftentimes practice what they do during "normal working hours." Even if they were so inclined, other times, like weekends and holidays, are frequently devoted to other activities such as family. In contrast, with a leisure component to their pursuit, amateurs are oftentimes involved in paleontology in the evenings (e.g., meetings), and on weekends and holidays (e.g., collecting fossils in the field). Likewise, geography is a barrier in places where amateurs and professionals do not live in close enough proximity to facilitate interaction on a regular basis. The following quotes are representative of these sentiments:

"Local availability of professionals, particularly in more remote areas."

"Finding time when they are both available-most amateurs are available after the typical working hours of professionals."

Finally, the lack of shared goals for why they do paleontology is perceived as a barrier:

"Different interest and goals_collecting fossils

(amateur) vs. answering research questions (professional)."

\section{Public participation and citizen science}

Several of the respondents, presumably amateurs, expressed interest in citizen science and how they could be more involved:

"...some of us would also be interested to know how to get involved in more advanced hard science."

"Enlist possible volunteers for future projects."

Likewise, a presumed professional commented that s/he would:

"Include citizen scientists in my research."

In fact, the community seems poised to be more involved in public participation; $78 \%$ of respondents answered that they would like to contribute to fossil digitization and/or do citizen science. The potential mutual benefits to citizen science and public participation are multifaceted and significant (Bonney et al., 2009; Dickinson et al., 2012; Ellwood et al., 2015). For the amateur it means direct involvement in the practice of paleontological research and for the professional it results in support for, and advancing the objectives of, programs that could always use more resources. Seventy percent of respondents indicated interest in discovering paleontological projects in which they could individually participate. Furthermore, from a broader point of view, this engagement results both in more active learning and advancing the science of paleontology. 


\section{Content of Future Activities (\%)}

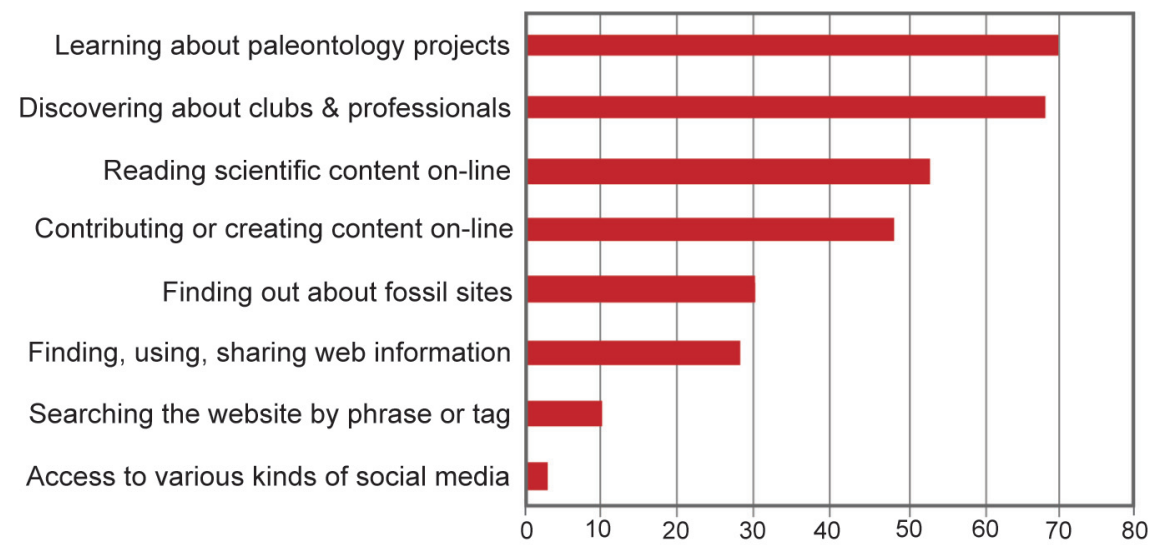

Real World Future Activities (\%)

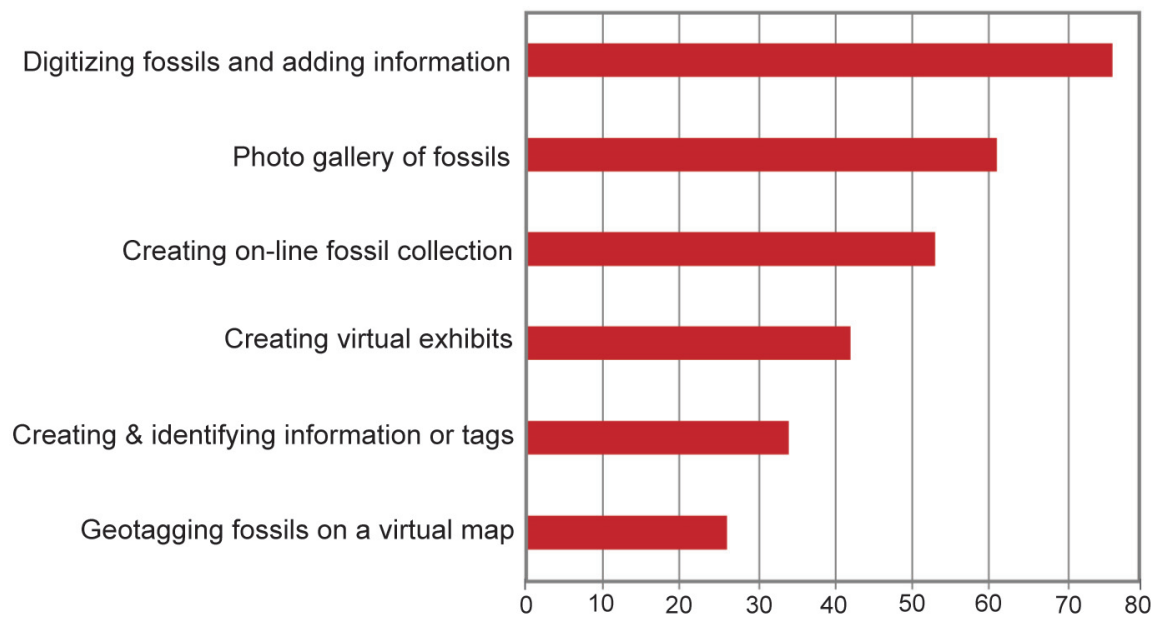

FIGURE 4. (Top) Percentage of total responses $(\mathrm{N}=40)$ about content and information preferences for future activities that might be mediated by FOSSIL. (Bottom) Examples of real-world (practical) skills for future activities.

\section{Taking action and moving forward}

In the few weeks following the NAPC and FOSSIL Kickoff meeting, participants were surveyed to determine if they had taken some action following the conference. Twenty-eight percent of respondents indicated they had taken some kind of action, with the largest response being "community outreach."

"Began to think of ways to have fossil clubs work with schools..."

"I submitted grant proposal to paleo society for education \& outreach"

Developing community is a fundamental aspect of the FOSSIL project. Eighty-five percent of amateurs said they were likely to follow up with someone they met at the conference or during the FOSSIL activities. Thus, an expectation of the NAPC Kickoff was at least realized by quotes such as:

"Now that I have met some people in other clubs, we are actively communicating and networking."

With regard to future activities, we asked respondents to discuss: (1) content they would like to see developed; (2) training they would like to receive; and (3) kinds and styles of communication they would like as FOSSIL moves forward.

As indicated in Figure 4, there was unanimous agreement among respondents about the kind of content and information they would like to see as the FOSSIL network further develops. A predominant theme, particularly among the more common 


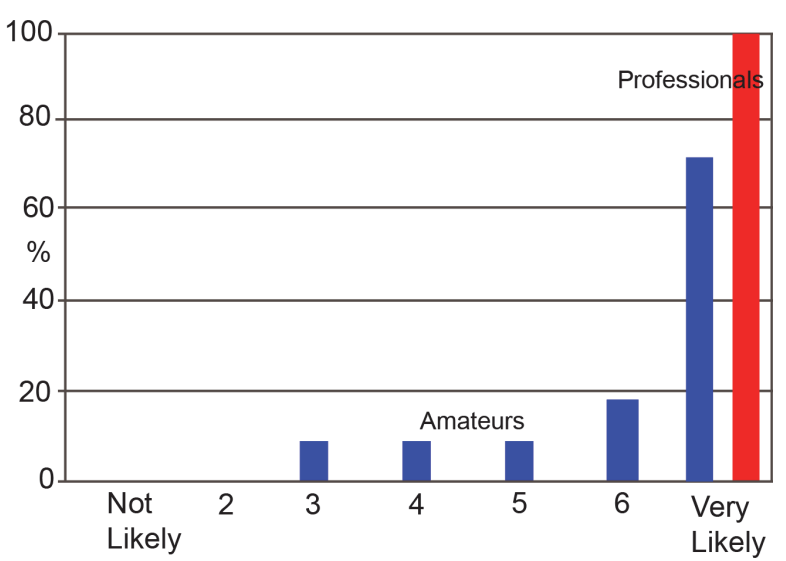

FIGURE 5. Likelihood of future participation in the FOSSIL project for amateurs and professionals who participated in our formative evaluation.

activities of the future, includes learning and discovering about paleontology. This bodes well not just for learning but also for developing the FOSSIL CoP along common themes, goals, and objectives. We also asked respondents to rank their preferences for "real-world" practical skills and activities in which they would like to participate. The most frequent responses involve digitization and photography of fossils.

Seventy-eight percent of respondents expressed a desire to participate in training webinars. Ninety percent of respondents indicate they plan to collaborate with other amateurs or professionals. On a seven point scale (Figure 5), 93\% of the amateurs ranked their expected engagement in the FOSSIL project as 6 or 7 (Very Likely). In the same vein, all of the professionals rated their interest in participation at 7, or "Very Likely."

In summary, the overwhelming pattern of these results indicates a high degree of potential participation for the amateurs and professionals surveyed. There also are strong interests in topics that could be the glue to bind a CoP, including advancing the science of paleontology, digitization, and photography. This learning will likely be delivered through different modalities, including both face-to-face and cyberenabled communication. The results of the formative evaluation further demonstrate the strong support for the continued development of a network of amateur and professional paleontologists in the USA.

\section{NETWORKING AND SOCIAL MEDIA WITHIN THE FOSSIL COMMUNITY}

\section{Analysis of social media}

When we originally envisioned the FOSSIL project in 2012, we thought that our primary means of communication and networking, i.e., other than during face-to-face meetings, field trips, and social events, would be the website and e-newsletter. We were unsure the extent to which our two target audiences would embrace social media such as Facebook and Twitter. Indeed the results of the front-end evaluation conducted in mid-2013 (Crippen et al., 2016) indicated a relatively low priority, or spotty usage, placed on these forms of communication by our community. The results of our formative evaluation in 2014 after NAPC likewise did not indicate a groundswell of social media communication, although one respondent stated:

"Our club for whom I represent has now activated social media as a result of what we learned at FOSSIL."

Although we might not have predicted it from the survey results, the social media aspect of the FOSSIL CoP has grown so rapidly since our formative evaluation conducted in 2014 that it makes sense to summarize the current status of these activities.

Currently, the FOSSIL project maintains ties with 39 amateur fossil and paleontological organizations. Preliminary analysis of amateur paleontological organizations indicates that $24(62 \%)$ maintain a Facebook presence, although two pages have not been updated since 2013, and three are closed Facebook groups that organizations cannot join. Further analysis is needed to specify the ways in which these organizations use Facebook to interact with their members. FOSSIL project social media research is currently focused on how amateur and professional paleontologists interact with the FOSSIL project's social media sites (Lundgren et al., 2015).

Following the NAPC at the end of February 2014, the FOSSIL project began systematically creating content for social media, specifically Twitter and Facebook. In order to reach amateur and professional paleontologists via social media, FOSSIL posted on both Facebook and Twitter social media accounts twice a day, using dedicated daily hashtags (e.g., \#MammothMonday). Communication via social media is typically categorized by levels of engagement (Kang, 2014; Smith and Gallicano, 2015). On Facebook, levels of engagement range from lowest to the highest as follows: 


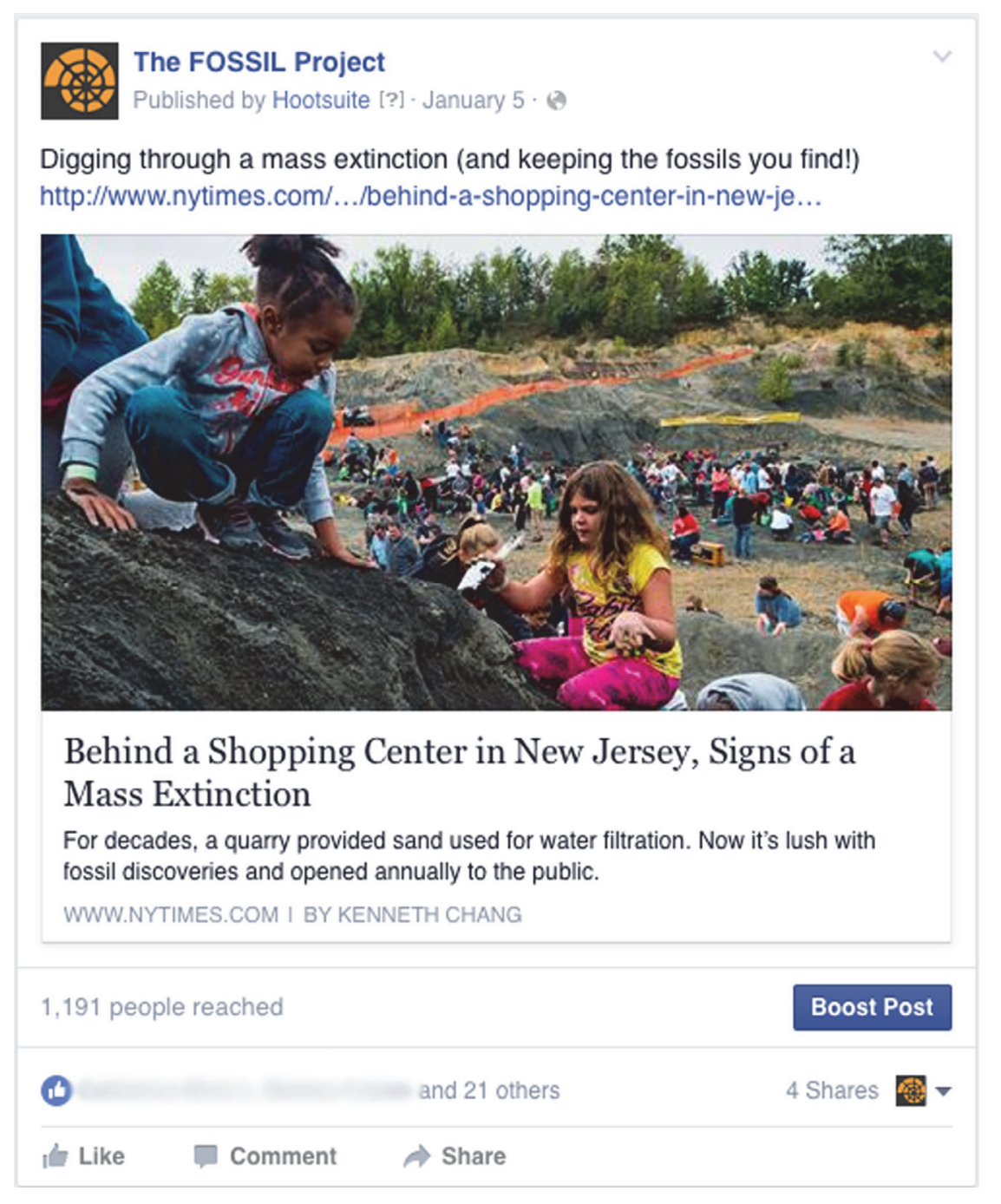

FIGURE 6. A paleontological news story as a FOSSIL project Facebook post. Note the number of people reached $(1,191)$, as well as the levels of engagement (23 likes, 4 share).

liking a post, sharing a post, or commenting on a post. When a Facebook user "likes" a post they are showing their approval. Facebook users typically share posts to communicate or inform their fellow Facebook users about relevant topics or to spread a message. Comments on posts are responses that may be positive, neutral, or negative.

Previous research has shown that users will engage in discussions about socio-scientific topics on social media (Greenhow et al., 2015). Our preliminary study of engagement (Lundgren et al., 2015) on Facebook follows a model described by Fauville et al. (2014). Post variance in the form of length, word choice, usage of pictures, and changes in content were examined to quantify our online audiences' levels of engagement with social media. This engagement was measured by the number of "likes," "shares," and "comments" per post. Based on these forms of engagement, additional social media posts were created for our target audience. In order to encourage engagement in the form of likes, shares, and comments, the FOSSIL Facebook page includes four different types of posts: (1) about research, (2) paleontological news stories, (3) featuring opportunities to participate in social paleontology, and (4) general information. Twitter features the same types of posts, but the content is limited to no more than 140 characters. A new post comes from media such as the New York Times Facebook Page (Figure 6). On Facebook, our preliminary data indicate that news posts (\# 2 above) result in more engagement (likes, shares, and comments) than any other post type. 


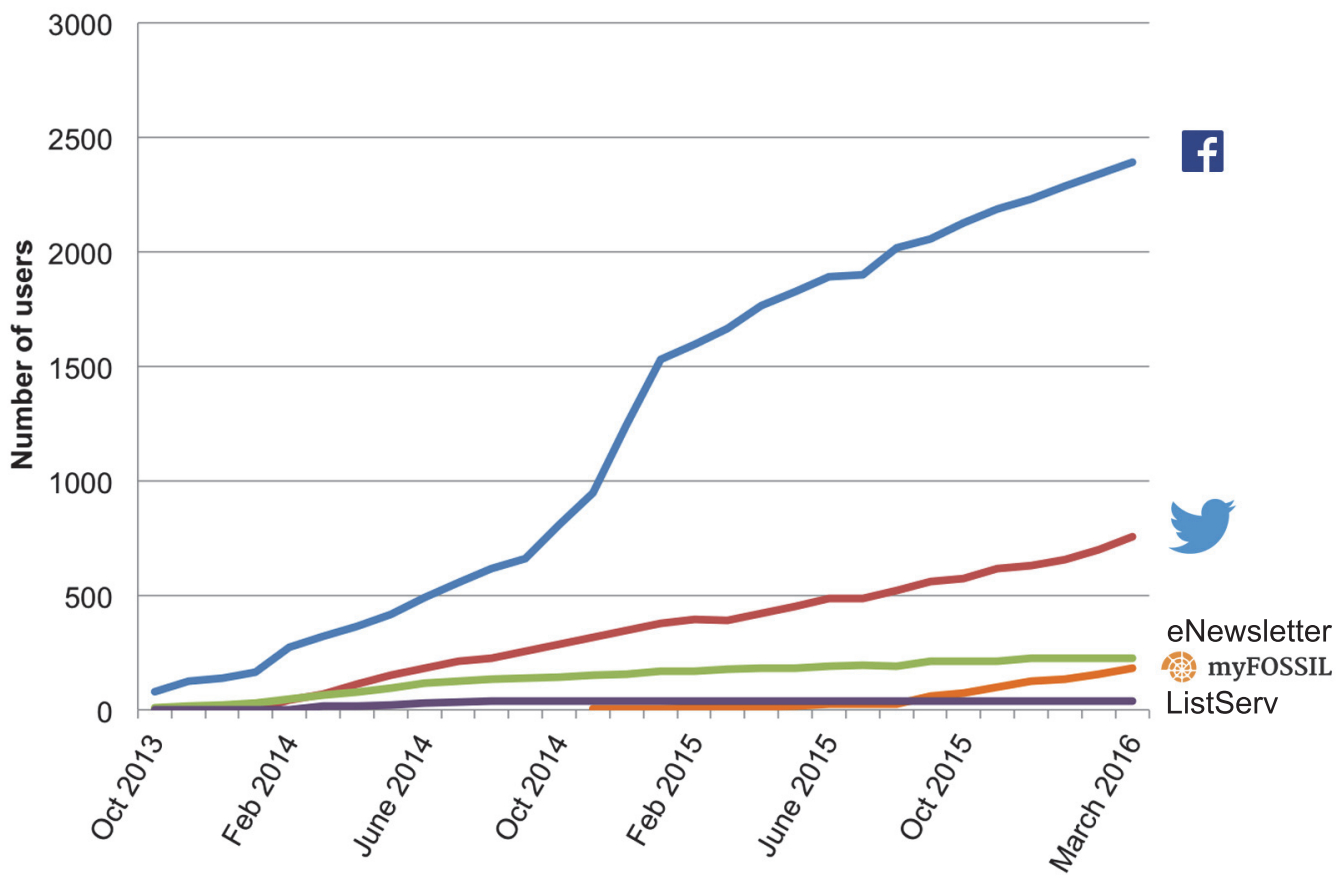

FIGURE 7. Comparison of the growth in the following modes of communication for the FOSSIL project: Facebook likes, Twitter followers, e-newsletter subscribers, Listserv subscribers, and FOSSIL project website, www.myfossil.org.

In posts that encourage Facebook users to join in social paleontology (opportunity posts), users also like, comment, and share, though the levels of engagement are less than the levels featured in news-centered posts. However, the most common form of engagement is the lowest form, i.e., liking a post (Lundgren et al., 2015). In this form of engagement, users do not describe the reasons they appreciate the post or the aspects of the post that kept them engaged, nor do they attempt to elicit conversation with others about the post.

In addition to creating and analyzing posts on the FOSSIL project's social media, we also investigated the forms of online communication that the FOSSIL project maintains with amateur and professional paleontologists. The original forms of remote communication for the FOSSIL project, i.e., a listserv and e-newsletter, have not seen much growth in comparison to the social media pages (Figure 7). As of the end of March 2016, the FOSSIL listserv reached only 37 people, while the enewsletter had 226 subscribers (Figure 7). On the other hand, as of the end of March 2016, the FOSSIL Twitter page had 757 followers while 2390 people "like" the FOSSIL Facebook page. The number of Facebook likes and Twitter followers measure the number of people who choose to see the content of the FOSSIL project's social media pages (i.e., content that appears in their news feeds). However, due to Facebook's updates for pages, users need to ensure that they click "get notifications" when they "like" the FOSSIL project in order to ensure that the FOSSIL project's posts are made available to them. As noted with the analysis on post types and engagement, while the network of Facebook likers is large, their levels of engagement remain low within FOSSIL.

Since the inception of the FOSSIL project we have developed a website, which until recently was used primarily for one-way (non-interactive) information and announcements, as well as a platform to host Facebook and Twitter. In mid-2015 we developed the myFOSSIL online "Social Paleontology" community site (www.myfossil.org) where members can assemble, interact, collaborate, and engage in activities related to science, community development, and outreach through web 2.0 and customized social media activities and interactions. We currently are in our community-building (postbeta) testing phase and, as of March 2016, have about 180 internal users (Figure 7). The rate of growth of internal (registered) members on our website is similar (i.e., compare slopes in Figure 7) 


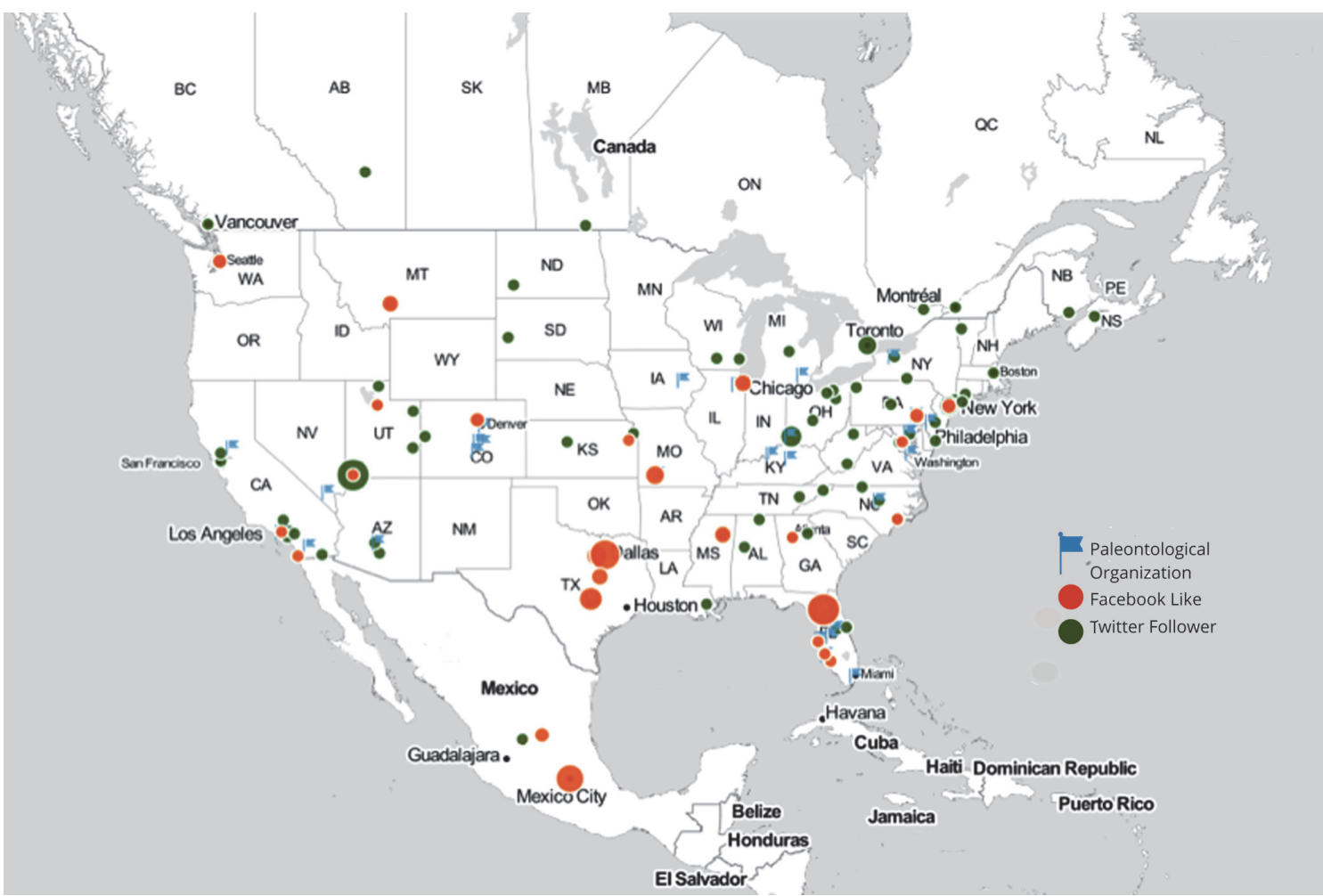

FIGURE 8. Map of amateur paleontological organizations, Facebook likes, and Twitter followers.

to our Twitter followers. Our website hosts users from across the USA, including, in particular, users from California, Florida, and Maryland. While it is fairly easy to determine where myFOSSIL website users are from, deductions about the geography of FOSSIL Facebook and Twitter communities is more complex because many of these latter users hide their locations due to privacy concerns. This is not unique to the FOSSIL project social media users; it is a common theme across social media research (Sun et al., 2014). While our research cannot currently identify the locations of all social media followers, it can elucidate some geographical patterns with regard to the FOSSIL project.

Facebook likes and Twitter followers tend to be concentrated where the FOSSIL project's network of organizations are found. For example, Florida and Texas feature a larger number of Facebook likes. This is perhaps not surprising because our data indicate that Florida includes eight different amateur fossil organizations, half of which have a Facebook page. This large number of fossil organizations paired with a robust social media presence can account for the number of Facebook likes (and Twitter followers) in Florida. In Texas, two different organizations, located in Austin and Dallas, have active Facebook pages as well as active member- ships. In contrast to the correlation between organizational presence and social media activity, a large Facebook following occurs in Mexico City (Figure 8), which lacks any fossil clubs or paleontological organizations in our network. We have yet to explain the reason for this active part of the FOSSIL social media community.

\section{CONCLUDING COMMENTS: SYNTHESIS AND MOVING FORWARD}

The results of the formative evaluation described above, also framed by Crippen et al. (2016) and from other qualitative observations during the past several years, have provided valuable insight about how to move forward building a FOSSIL learning community of practice (CoP) and developing best practices for involving amateur and professional paleontologists. Some themes and topics that have emerged include the following:

\section{Communication}

Our data indicate that-unlike birdwatchers and stargazers-amateur paleontologists are not networked nationally. We also know that the majority of our target audience connects, or has the capacity to connect, via email and/or the web. We 
are likely to see limited growth in the number of people interested in paleontology who will learn about, and engage in, relevant activities using our list-serve, or opt to receive our e-newsletter. The most exciting increase in communication with our audiences will almost certainly come from social media, including FOSSIL Facebook and Twitter, both of which have realized steady gains since 2013 (Figure 7). If recent trends continue, then we also expect to see increased activity from our myFOSSIL web portal on a trend similar to that of our Twitter.

\section{Building a community of practice}

Wegner et al. (2002) describe a Community of Practice as a group of people who share a concern, set of problems, or a passion about a topic, and who deepen their knowledge and expertise on an ongoing basis. Within this context, the FOSSIL stakeholders form a cohesive group with common goals and interests that include promoting the science of paleontology, collecting fossils, learning, and dissemination. Nevertheless, even with common goals, the lack of mutual trust and respect among some participant stakeholders represents a real barrier to forming a cohesive FOSSIL CoP. We have identified that, although not pervasive, there is an undercurrent of trust that must be addressed. The reasons for trust issues are numerous and varied, although they primarily relate to different goals and interests of amateur paleontologists on the one hand and professional paleontologists on the other hand.

\section{Social paleontology}

The results of the formative evaluation support the need for multiple forms of technology for contributing to social paleontology, including the continued use of popular social media as well as the myFOSSIL online community site. Through our analysis of engagement patterns we find support for the three themes that represent the practice of social paleontology: making connections, making observations, and having conversations. However, it is incorrect to assume that all content is equally engaging within the CoP. Although the community has demonstrated interest and engagement with a range of post types, the level and type of engagement with news posts indicates investment in only one, limited dimension of paleontology. As a technology steward for the community, the FOSSIL project has a role to play in establishing communi- cation strategies that provide access to the full spectrum of paleontological inquiry. We also realize that other existing online communities have focused on meaningful discourse. For example, the Fossil Forum (www.thefossilforum.com), which has a large world-wide reach, has provided a valuable mode of communication about paleontology and related topics.

\section{Diversity and demographics}

More than half of the clubs self-identify as not particularly diverse in terms of age and ethnicity. Thus the vast majority consists predominantly of white members. The only minority representation is Hispanic/Latino in regions where they are well represented in the general population. Another characteristic is the lack of younger members (e.g., teens through about 30 years of age), and thus some clubs have expressed concern about sustaining their organizations into the future. Although there is no systematic study in the USA about this issue, in the United Kingdom a survey of informal science institutions "...found that almost seven out of ten respondents had experienced difficulties engaging with one or more audience groups, and the high-level findings suggested that adults aged over 19, families and young people aged 12-19 were the most challenging groups (Lloyd et al., 2012 , p. 4). This latter demographic is one we recognize as disengaged in fossil clubs and paleontological societies, although that may be changing with the advent of social paleontology. Of relevance to this point, a Pew Charitable Trust (2010) survey found that the highest level $(75 \%)$ of social media usage occurs within Millennials (18 to 29), and presumably the $<18$ year-old demographic as well. With this background in mind, fossil clubs seeking new, younger members might want to elevate their social media usage to attract these under-represented participants.

Another at-risk segment of learners generally includes adolescent girls, which studies have shown tend to significantly decrease their interest and engagement in science (Munley and Rossiter, 2012). This is therefore another contributing factor that can result in the issue with involving the younger learners into fossil club activities. Recent initiatives, such as Women's Day in Paleontology sponsored by the Florida Fossil Hunters (2015) based in Orlando, seek to promote women continuing in paleontology through activities led by appropriate role models. 


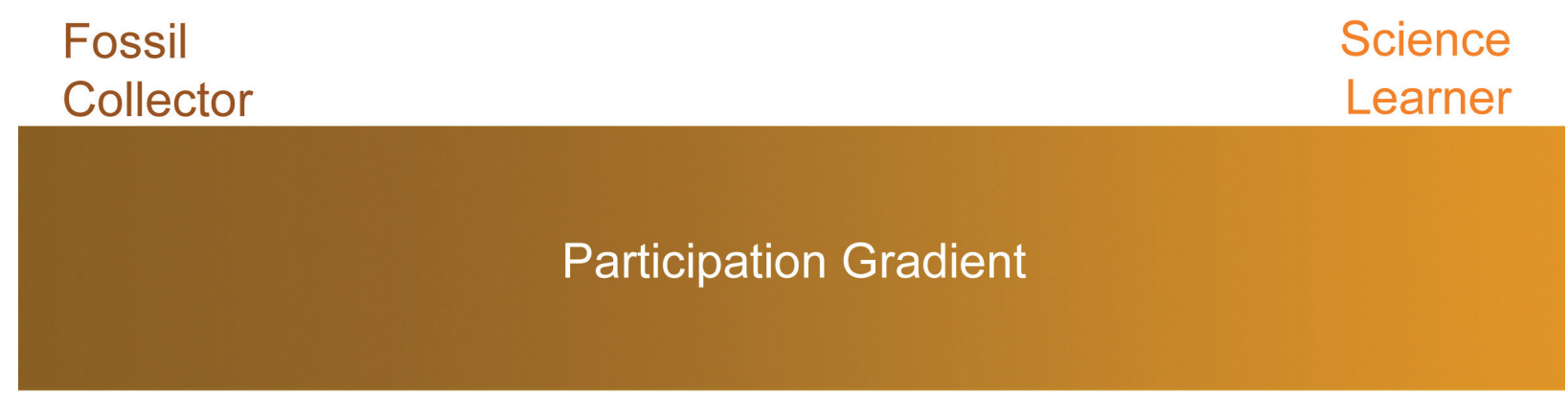

FIGURE 9. Theoretical model of the end-members and spectrum of motivations for participating in paleontology.

\section{STEM learning, content, and skills development}

Our qualitative observations of the motivation for why amateurs collect fossils and participate in organized activities span a spectrum (Figure 9). The two end-members range from the thrill of the discovery in the field (Fossil Collector) on the one end to the desire to learn (Science Learner) about extinct life of the past on the other end. While the former requires some basic identifying skills, it also is potentially of great benefit to those participants who are primarily interested in the practice of paleontology. In theoretical contrast, the latter, i.e., the desire to learn, has the potential for deep STEM learning, including those topics that are of current societal relevance (Leshner, 2010) like evolution and climate change. In reality, it is likely that most amateur paleontologists fall somewhere in between the end-members represented in Figure 9. While it is not the goal of the FOSSIL project to make everyone primarily a deep learner, the project does seek to provide the context in which advances in STEM knowledge and engagement are possible with those participants who might be interested.

In addition to general interest in geology and paleontology, fossil club and society participants have a special interest in the practice of documenting their fossil collections. Likewise, the skills related to the photographing and digitizing collections are primarily relegated to the professional realm, whereas there is great interest among the amateurs as they desire to build and deepen their expertise in this aspect of paleontology. A "go-to" place to find such training and expertise is currently lacking for interested participants. In a model similar to the concept of professional development, the FOSSIL project views these training opportunities as professional development of a cadre of committed amateurs in our CoP.

\section{Digital fossil collections in the twenty-first century}

Tens, if not hundreds, of million fossils are housed in research collections in natural history museums in the USA; there is even less known about how many fossils are contained in private collections. Recent initiatives such as iDigBio (2015, also Page et al., 2015) for non-federally supported collections and BISON (2015) for federal collections, are moving towards digitizing fossils in the public domain and making them broadly accessible, e.g., in web-based cloud portals. In addition to enhancing access for research by professional paleontologists, another added value to digitized fossil collections is that they then become available to downstream users, including amateur paleontologists (e.g., Hendricks et al. 2015).

Fossil collections and their objects, i.e., the specimens themselves, are the glue that binds together the amateur and professional paleontological communities. Thus, our surveys indicate that although amateurs are relatively uninformed about the details and process of digitization, they have high levels of interest. This bodes well for the development of the amateur community with regard to helping professionals digitize research collections. It also should enhance learning how to digitize their own collections for personal use, access for other activities like K-12 outreach, or if desirable, for donation to a permanent repository. In so doing, the collaborative process between amateurs and professionals within the CoP also promotes public engagement and understanding of science.

\section{Summary}

The data we have assembled and observations we have made indicate meaningful potential for continuing to build a learning CoP that includes amateur and professional paleontologists mediated within the context of social paleontology. In so 
doing, we can build upon other successful national models like those developed for other lifelong learning interest groups, e.g., within astronomy and ornithology. In addition, the FOSSIL CoP will also engage participants in another kind of data and knowledge acquisition, one that involves physical and vouchered paleontological collections located in US natural history museums and their digitized counterparts in the cloud. These activities include twenty-first century skills, with increasing emphasis on web-based learning and communication as well as related social media to engage diverse stakeholders.

\section{ACKNOWLEDGMENTS}

This research and the related FOSSIL project have been supported by US NSF (National Science Foundation) 1322725 (DRL). We thank the many survey participants, including fossil club members, amateurs, professionals, and other stakeholders who have contributed to this initiative and for their thoughtful input. A.J.W. and K. Hendy participated in the initial phases of the development of FOSSIL. C. Grant helped with some of the graphics. Our external project evaluators and advisors K. Haley Goldman and S. Yalowitz of Audience Viewpoints Consulting (AVC, 2015) developed, administered, and analyzed the formative survey conducted in 2014 after the NAPC. The front-end and formative protocols conducted during this study were approved by the University of Florida Institutional Review Board. This is University of Florida Contribution to Paleobiology number 824.

\section{REFERENCES}

Archangelsky, S., Edwards, D., Gall, J.-C., Lipps, J.H., and Ashley, G.M. 2000. Societies, p. 109-113. In Lane, R.H., Steininger, F.F., Kaesler, R.L., Ziegler, W., and Lipps, J. (eds.), Fossils and the Future: Paleontology in the 21st century. Senkenberg-Buch Nr. 74., Frankfurt a. M.

ASTC (Association of Science - Technology Centers). 2016. Communities of practice, accessed on 24 March 2016 from www.astc.org/professional-development/communities-of-practice/

AVC. 2015. Audience Viewpoints Consulting, accessed 22 October 2015 at www.audienceviewpoints.com/

BISON. 2015. Biodiversity Information Serving Our Nation, accessed 21 September 2015 at bison.usgs.ornl.gov/\#home

Bonney, R., Cooper, C.B., Dickinson, J., Kelling, S., Phillips, T., Rosenberg, K.V., and Shirk, J. 2009. Citizen science: A developing tool for expanding science knowledge and scientific literacy. Bioscience, 59:977984.
Brown, R.W. 1956. The Composition of Scientific Words. Smithsonian Institution Press, Washington, D.C.

CAISE. 2016. Center for the Advancement of Informal Science Education, accessed 23 March 2016 at www.informalscience.org/

Catalani, J.A. 2014. Contributions by amateur paleontologists in 21st century paleontology. Palaeontologia Electronica, 17.2.3E: 4p; palaeo-electronica.org/content/2014/768-contributions-by-amateur-paleontologists

Crippen, K.J., Ellis, S., Dunckel, B.A., Hendy, A.J.W., and MacFadden, B.J. 2016. Seeking shared practice: A juxtaposition of the attributes and activities of organized fossil groups with those of professional paleontology. Journal of Science Education and Technology, accepted.

DOI: 10.1007/s10956-016-9627-3

Cunningham, J.A., Rahman, I.A., Lautenschlager, S., Rayfield, E.J., and Donoghue, P.C.J. 2014. A virtual world of paleontology. Trends in Ecology \& Evolution, 29:301-368.

Diamond, J., Luke, J.J., and Uttal, D.H. 2009. Practical Evaluation Guide: Tools for Museums and Other Informal Educational Settings. Lanham, Maryland, Altimira Press.

Dickinson, J.L., Shirk, J., Bonter, D., Bonney, R., Crain, R.L., Martin, J., Phillips, T., and Purcell, K. 2012. The current state of citizen science as a tool for ecological research and public engagement. Frontiers in Ecology and the Environment, 10:291-297. dx.doi.org/10.1890/110236

Ellwood, E.E., Dunckel, B.A., Flemons, P., Guralnick, R., Nelson, G., Newman, G., Newman, S., Paul, D., Riccardi, G., Rios, N., Seltmann, K., and Mast, A.R. 2015. Accelerating the digitization of biodiversity research specimens through online public participation. Bioscience, doi: 10.1093/biosci/biv005

Falk, J.H. and Needham, M.D. 2013. Factors contributing to adult knowledge of science and technology. Journal of Research in Science Teaching, 50:431452.

Falk, J.H., Storksdieck, M., and Dierking, L.D. 2007. Investigating public science interest and understanding: evidence for the importance of free-choice learning. Public Understanding of Science, 16:455-469.

Fauville, G., Dupont, S., von Thun, S., and Lundin, J. 2014. Can Facebook be used to increase scientific literacy? A case study of the Monterey Bay Aquarium Research Institute Facebook page and ocean literacy. Computers \& Education, 82:60-73.

Ferrara, C. 2015. Club corner: Southwest Florida Fossil Society. The Fossil Project Newsletter, 2(2):8-9, accessed 12 July 2015 at www.myfossil.org/ archived-newsletters/

Florida Fossil Hunters. 2015. Accessed 17 September 2015 at www.floridafossilhunters.com/

Gongla, P. and Rizzuto, C.R. 2001. Evolving communities of practice: IBM Global Services experience. IBM 
Systems Journal, 40:842-862.

doi:10.1147/sj.404.0842

Greenhow, C., Gibbins, T., and Menzer, M. 2015. Rethinking scientific literacy out-of-school: Arguing science issues in a niche Facebook application. Computers in Human Behavior, 53:593-604.

Hendricks, J.R., Stigall, A.L., and Lieberman, B.S. 2015. The Digital Atlas of Ancient Life: delivering information on paleontology and biogeography via the web. Palaeontologia Electronica, 18.2.3E:1-9.

Hesemann, M. 2015. The foraminifera.eu database: concept and status. Palaeontologia Electronica, 18.3.48A: 1-14.

Hooks, G.E., III. 2005. The importance of the amateur paleontologist, p. 187-188. In Buta, R.J., Rindsberg, A.K., and Kopaska-Merkel, D.C. (eds.), Pennsylvanian Footprints in the Black Warrior Basin of Alabama. Alabama Paleontological Society Monograph, Birmingham, no. 1.

iDigBio (Integrated Digitized Biodiversity Collections). 2015, accessed 21 September 2015 at https:// www.idigbio.org/

Kang, M. 2014. Understanding public engagement: Conceptualizing and measuring its influence on supportive behavioral intentions. Journal of Public Relations Research, 26:399-416.

Kienle, A. and Wessner, M. 2005. Principles for Cultivating Scientific Communities of Practice, p. 283-299. In Besselaar, P., Michelis, G., Preece, J., and Simone, C. (eds.), Communities and Technologies 2005. Springer, Netherlands.

Larson, N.L., Stein, W., Triebold, M., and Winters, G. 2016. What commercial fossil dealers contribute to paleontology. Journal of Paleontological Sciences, Issue \# 10, accessed 5 April 2016 at www.aaps-journal.org/Fossil-Dealer-Contributions.html

Lave, J. and Wenger, E. 1991. Situated Learning: Legitimate Peripheral Participation. Cambridge University Press, New York.

Leshner, A. 2010. Scientists and science centers: A great glocal [sic.] partnership opportunity. Talk SA 23 at Association of Science-Technology Centers (ASTC) Annual Meeting, Honolulu, Hawaii, October 2-5, 2010; also see published article "Scientists and science centers: A great 'glocal' partnership opportunity." ASTC Dimensions, November/December 2010, p. 4-5.

Lloyd, R., Neilson, R., King, S., and Dyball, M. 2012. Science beyond the classroom: Review of Informal Science Learning. Prepared for the Wellcome Trust, London UK, 110 p., accessed 24 March 2016 at www.wellcome.ac.uk/stellent/groups/corporatesite/ @msh_peda/documents/web_document/ wtp040862.pdf

Lundgren, L.M., Crippen, K.J., MacFadden, B.J., Dunckel, B., Ellis, S., and Gardner, E.E. 2015. Exploring social media as a research tool for measuring engagement in a paleontological community of practice. Presentation at the Annual Geological Soci- ety of America Meeting, Baltimore, Maryland, abstract accessed on 24 March 2016 from: https:// gsa.confex.com/gsa/2015AM/webprogram/ Paper262961.html

Manfreda, K.L., Bosnjak, M., Berzelak, J., Hass, I., and Vehovar, V. 2008. Web surveys versus other survey modes: A meta-analysis comparing response rate. International Journal of Market Research, 50:79-104.

Munley, M.E. and Rossiter, C. 2012. Girls, Equity and STEM in Informal Learning Settings A Review of Literature, accessed 18 September 2015 at stem.arizona.edu/sites/stem.arizona.edu/files/ SAVI\%20Lit\%20Review\%20Oct\%202013\%20Girls\%20STEM.pdf

National Research Council. 2009. Learning Science in Informal Environments: People, Places, and Pursuits. Committee on Learning Science in Informal Environments. In Bell, P., Lewenstein, B., Shouse, A.W., and Feder, M.A. (eds.), Board on Science Education, Center for Education. Division of Behavioral and Social Sciences and Education. The National Academies Press, Washington, D.C.

Page, L.M., MacFadden, B.J., Fortes, J.A., Soltis, P.S., and Riccardi, G. 2015. Digitization of biodiversity collections reveals biggest data on biodiversity. Bioscience, doi 10.1093/biosci/biv104

Pew Charitable Trust. 2010. Millennials: Confident. Connected. Open to Change, accessed 18 September 2015 at www.pewsocialtrends.org/2010/02/24/millennials-confident-connected-open-to-change/

Plotnick, R.E. 2007. SWOTing at paleontology. American Paleontologist, 15(4):21-23.

Pringle, H. 2014. Selling America's fossil record. Science, 343:364-367.

Priscum, 2016. Newsletter of the Paleontological Society, accessed on 02/29/2016, paleosoc.org/

Shih, T. and Fan, X. 2008. Comparing response rates from web and mail surveys: A meta-analysis. Field Methods, 20:249-271.

Shimada, K., Currie, P.J., Scott, E., and Sumida, S. 2014. The greatest challenge to $21^{\text {st }}$ century paleontology: When commercialization of fossils threatens the science. Palaeontologia Electronica, accessed 5 April 2016 at: palaeo-electronica.org/content/pdfs/comment_threat.pdf

Smith, B. and Gallicano, T. 2015. Terms of engagement: Analyzing public engagement with organizations through social media. Computers in Human Behavior, 53:82-90.

Sun, N., Rau, P., and Ma, L. 2014. Understanding lurkers in online communities: A literature review. Computers in Human Behavior, 38:110-117.

SVP (Society of Vertebrate Paleontology). 1940-2010. New Bulletin. vertpaleo.org/CMSPages/PortalTemplate.aspx?aliaspath=/Publications/SVP-News-Bulletin

Uhen, M.D., Barnosky, A.D., Bills, B., Blois, J., Carrano, M.T., Carrasco, M.A., Erickson, G.M., Eronen, J.T., 
Fortelius, M., Graham, R.W., Grimm, E.C., O'Leary, M.A., Mast, A.R., Piel, H., Polly, P.D., and Säilä, L.K. 2013. From card catalogs to computers: Databases in vertebrate paleontology. Journal of Vertebrate Paleontology, 33:13-28

dx.doi.org/10.1080/02724634.2012.716114

US Department of Education. 2011. Connect and inspire: Online communities of practice in education. Retrieved from Washington, DC: connectededuca-
tors.org/report/files/2011/03/0143_OCOP-Mainreport.pdf

Wenger, E. 1998. Communities of Practice: Learning, Meaning, and Identity. Cambridge University Press, Cambridge, U.K.

Wenger, E., McDermott, R., and Snyder, W.M. 2002. A Guide to Managing Knowledge: Cultivating Communities of Practice. Harvard Business School Press, Boston. 